\title{
ALLOGRAFT HEART VALVES: THE ROLE OF APOPTOSIS-MEDIATED CELL LOSS
}

Stephen L. Hilbert, MD, PhD

Rafael E. Luna, BS

Jun Zhang, MD

Yining Wang, MD

Richard A. Hopkins, MD

$\mathrm{Zu}-\mathrm{Xi} \mathrm{Yu}, \mathrm{MD}, \mathrm{PhD}$

Victor J. Ferrans, MD, PhD
Objective: The purpose of this study was to determine whether apoptosis of endothelial and connective tissue cells is responsible for the loss of cellularity observed in implanted aortic allograft valves. Methods: Fresh (n $=6)$ and cryopreserved $(n=4)$ aortic allograft valves were retrieved at 2 days to 20 weeks after implantation in an ovine model. Sections of these valves were studied with the use of histologic and electron microscopic methods, nick end-labeling and dual immunostaining for factor VIII-related antigen and proliferating cell nuclear antigen, followed by counterstaining for DNA and laser scanning confocal fluorescence microscopic observation. Results: The endothelial cells and cusp connective tissue cells of implanted valvular allografts showed loss of proliferating cell nuclear antigen (indicative of cessation of mitotic activity) and evidence of apoptosis (nick end labeling). The latter was manifested by nuclear condensation and pyknosis, positive nick end labeling, and formation of intra- and extracellular apoptotic bodies derived from the fragmentation of apoptotic cells. These changes began to develop at 2 days after implantation, peaking at 10 to 14 days, and became complete by 20 weeks, at which time the valves had the typical acellular morphologic features of allografts implanted for long periods of time. Conclusions: Apoptosis occurs in endothelial cells and cuspal connective tissue cells of implanted allografts and appears to be a cause of their loss of cellularity. This apoptosis may be related to various factors, including immunologic and chemical injury, and hypoxia during valve processing and reperfusion injury at the time of implantation. ( $J$ Thorac Cardiovasc Surg 1999;117:454-62)
$T^{n}$ he use of allografts for the replacement of diseased cardiac valves and for the reconstruction of the right ventricular outflow tract has increased considerably during the last decade, and numerous studies have

From the Center for Devices and Radiographical Health, Food and Drug Administration, Rockville, Md; the Pathology Section, National Heart, Lung, and Blood Institute, National Institutes of Health, Bethesda, Md; the Department of Surgery, Georgetown University Medical Center, Washington, DC; and the Department of Surgery, Brown University, School of Medicine, Providence, RI.

The opinions or assertions are the private views of the authors and are not to be construed as conveying either an official endorsement or criticism by the US Department of Health and Human Services, the Food and Drug Administration, or the National Institutes of Health.

Received for publication May 6, 1998; revisions requested July 10, 1998; revisions received Oct 5, 1998; accepted for publication Oct 7, 1998.

Address for reprints: Stephen L. Hilbert, MD, PhD (HFZ-150), Center for Devices and Radiological Health, Food and Drug Administration, 9200 Corporate Blvd, Rockville, MD 20850.

Copyright $\odot 1999$ by Mosby, Inc.

$0022-5223 / 99 \$ 8.00+0 \quad \mathbf{1 2 / 1 / 9 5 0 2 6}$ demonstrated the long-term durability of cryopreserved allograft valve. ${ }^{1}$ Cryopreservation techniques have been designed to maximize the viability of the endothelial cells and connective tissue cells, based on the premise that this viability is an important factor in maintaining the structural integrity of these valves over prolonged periods of time. Nevertheless, evidence that cellular viability can be maintained in allografts implanted for extended periods of time has not been convincing, and morphologic studies have consistently demonstrated that such grafts eventually become completely acellular, except for the presence of fibrous sheathing composed of cells and extracellular matrix components of host origin. ${ }^{2,3}$ The mechanism responsible for this loss of cells has not been identified. It is known that morphologic and metabolic changes consistent with hypoxic damage develop during the period of time involved in harvesting and processing of allografts. ${ }^{4,5}$ However, changes of a different type develop gradually in the endothelial cells and connective tissue cells (fibroblasts and myofibroblasts) after implantation and consist of 
severe nuclear pyknosis., ${ }^{2,3}$ This pyknosis is followed by a gradual loss of cellularity and is morphologically similar to the nuclear condensation that is characteristic of the initial phase of apoptosis. ${ }^{6}$ We initiated the present study to evaluate the possibility that apoptosis is responsible for the loss of cell viability observed in fresh and cryopreserved allografts implanted in an ovine model. For this purpose, we have used electron microscopy, in situ nick end labeling, and immunohistochemical techniques in conjunction with confocal laser scanning fluorescence microscopy. ${ }^{3}$

\section{Methods}

Animal model. Both the donor and the recipient sheep were of the Dorset breed and were 4 months old, with a body weight of 38 to $40 \mathrm{~kg}$ at the time of the allograft harvesting and implantation. The investigational protocol used in this study was approved by the Animal Use and Care Committee of the Georgetown University Medical Center, and the animals received humane care in compliance with the principles stated in the Guide for Care and use of Laboratory Animals (NIH Publication No. 85-23). Immediately after death, within 1 minute of cardiac arrest, the entire heart was rapidly excised and immersed in cold saline solution (warm ischemic interval, approximately 1 minute for both the fresh and the cryopreserved allografts). The aortic root was then excised, with the heart and great vessels immersed in cold saline solution (as is done during the harvesting of human allograft valves) and either placed in RPMI 1640 medium at $4^{\circ} \mathrm{C}$ for up to 1 hour (fresh allograft) or disinfected and cyropreserved. The disinfection and cryopreservation protocols were identical to those used clinically. ${ }^{7}$ Disinfection was accomplished with the following antibiotics: cefoxitin, $240 \mu \mathrm{g} / \mathrm{mL}$; lincomycin, $120 \mu \mathrm{g} / \mathrm{mL}$; polymyxin $\mathrm{B}, 100 \mu \mathrm{g} / \mathrm{mL}$; and vancomycin, $50 \mu \mathrm{g} / \mathrm{mL}$, in RPMI 1640 medium. The aortic valves were immersed in the antibiotic-containing medium for 24 hours at $4^{\circ} \mathrm{C}$. The disinfected valves were subsequently transferred to RPMI 1640 medium containing $10 \%$ dimethylsulfoxide and $10 \%$ fetal calf serum and frozen at a controlled rate of $-1{ }^{\circ} \mathrm{C}$ per minute to between $-40^{\circ} \mathrm{C}$ and $-80^{\circ} \mathrm{C}$. The valves were then stored in liquid nitrogen vapor $\left(-190^{\circ} \mathrm{C}\right.$ to $\left.-150^{\circ} \mathrm{C}\right)$ until used. Fresh and cryopreserved sheep aortic allograft valves were implanted in the mid-thoracic aorta (left thoracotomy, fourth intercostal space) by means of proximal and distal end-to-end anastomoses after the temporary placement of a bypass shunt (to prevent spinal cord ischemia/paraplegia). A 5-mm expanded polytetrafluoroethylene vascular graft served as a shunt between the distal aortic arch (approximately $2-\mathrm{cm}$ proximal to the allograft anastomosis) and the left atrium. The use of this shunt raised the left atrial pressure to approximately 12 to $14 \mathrm{~mm} \mathrm{Hg}$ but did not result in the subsequent development of congestive heart failure in chronic ( 20 weeks) animals. The shunt served to increase the aortic pulse pressure by decreasing the diastolic pressure (eg, 10-15 $\mathrm{mm} \mathrm{Hg}$ ). The intraoperative peak diastolic pressure measured in the aorta, proximal to the allograft, with a cardiac output of $3 \mathrm{~L} / \mathrm{min}$, typically varied between 50 and $70 \mathrm{~mm} \mathrm{Hg}$. The placement of this shunt provided the appropriate hemodynamic conditions necessary to ensure the full range of leaflet motion and coaptation, as confirmed by Doppler echocardiography. The cusps were observed to simply flutter throughout the cardiac cycle when the aortic-left atrial shunt was crossclamped or occluded.

Included in this study were 15 sheep aortic valves: 5 native, unimplanted valves and 10 explanted allograft valved conduits. Six of these allografts were fresh, and the other 4 were cryopreserved. All animals were electively killed. Our investigational plan was designed to implant the long-term (20 weeks) allografts first and conduct the initial explant pathologic studies to assess the suitability of this experimental model. After the first series of 20 -week explants revealed that the cusps were essentially acellular, we modified the investigational plan, focusing our efforts on short-term explants, in the hope of capturing morphologic information that would provide an explantation for the relatively rapid loss of cuspal cellularity. The explanted allografts were studied after 2 days (fresh $[\mathrm{n}=1]$ and cryopreserved $[\mathrm{n}=1]$ ), 8 days (cryopreserved $[\mathrm{n}=1]$ ), 10 days (cryopreserved $[\mathrm{n}=1]$ ), 14 days (fresh $[n=1]), 30$ days (cryopreserved $[n=1]$ ), and 20 weeks (fresh $[n=4]$ ) of implantation.

Morphologic studies. Blocks of tissues fixed with phosphate-buffered $10 \%$ formalin were cut from the central third of the valve, extending from the base to the free edge, and were embedded in paraffin. From 20 to 30 consecutive sections of these blocks were used for histologic study and for the immunohistochemical staining procedure described later. For histologic study, the sections were stained with hematoxylin and eosin and Movat pentachrome stain. For immunohistochemical study, representative sections were stained for the simultaneous demonstration of (1) nick end labeling for the detection of apoptosis, by means of the incorporation of either fluorescein-labeled or biotinylated deoxynucleotides by terminal deoxynucleotidyl transferase (ApopTag direct in situ apoptosis detection kit [fluoresceinlabeled deoxynucleotides] catalog S7160-Kit; Oncor, Inc, Gaithersburg, Md; TACS-2, peroxidase kit; Trevigen, Gaithersburg, Md); (2) dual labeling for the simultaneous demonstration of factor VIII-related antigen (rabbit polyclonal antibody (DAKO Corp, Carpenteria, Calif), using a fluorescein isothiocyanate-conjugated secondary antibody (Vector Laboratories, Burlingame, Calif) and proliferating cell nuclear antigen (PCNA; antigen retrieval heating for a total of 15 minutes at $90^{\circ} \mathrm{C}$ ), in conjunction with a mouse monoclonal antibody (DAKO), using Texas red-conjugated secondary antibody, (Vector); and (3) DNA, using a $0.01 \%$ aqueous solution of 2,6'-diamidino-4-phenylindole (DAPI; Sigma Chemical Co, St Louis, Mo). Appropriate negative histochemical control procedures (omission of the primary antibody and substitution of normal goat or rabbit $\operatorname{IgG}$ for the primary antibody) were used in conjunction with each of these methods and gave negative results. Simultaneous 3-color fluorescence imaging (fluorescein, green; Texas red, red; and 
DAPI, blue) was accomplished with a laser scanning confocal fluorescence microscope (model TCS-4D-DMIR-BE; Leica, Heidelberg, Germany). For transmission electron microscopy (JEOL 100CX; JEOL USA, Peabody, Mass), valve tissues were fixed with glutaraldehyde and processed as previously described. ${ }^{8}$

\section{Results}

Histologic observations. The following histologic findings were similar in explanted fresh and cryopreserved allograft valves:

1. a marked reduction in cusp cellularity, which occurred within the first 30 days of implantation (Fig 1, $A$ and $B$ ) and was associated with condensation, pyknosis, and fragmentation of the nuclei (Fig 1, C);

2. an increase in cuspal thickness, primarily because of the formation of a fibrous sheath of host origin that initially consisted of a proteoglycan-rich matrix, fibroblasts, myofibroblasts, and a lining layer of endothelial cells (Fig 1,D);

3. infiltration of macrophages, which were diffusely distributed in the extracellular matrix and most numerous in valves implanted for 30 days or longer;

4. lymphocytes and plasma cells, which were rarely observed;

5. consistent loss of the continuity of the endothelial cell layer of the cusp;

6. progressive disruption of the structure of the cusps, with loss of the normally distinct boundaries between the ventricularis and the spongiosa after 30 days and 20 weeks of implantation, respectively (compare Fig $1, A, B$, and $D$ );

7. extensive mineralization of the aortic walls, without calcification of the cusps.

At 20 weeks, the cusps were markedly thickened and contracted because of extensive cellularity and deposition of collagen in fibrous sheaths (Fig 1,D). At this time, prominent regions of collagen straightening (elongation) without evidence of collagen fibril fracture had developed in the connective tissue of the cusp. Significant thickening and contraction of the fibrous sheaths resulted in either valvular insufficiency or complete immobilization of the cusps against the aortic wall.

As mentioned earlier, lymphocytes and plasma cells were rarely seen. However, in a single explant, focal infiltrates of lymphocytes and plasma cells were observed within the fibrosa near the cuspal surface and deep within the cusp. This finding was not observed in any of the other explanted valves in this series.
Immunohistochemical observations. A marked reduction in the mitotic activity of leaflet cells occurred within 2 days of implantation, as assessed by the loss of the PCNA reactivity normally present in the valvular endothelial cells and connective tissue cells (Fig 1, $E$ and $F$; Fig 2, A). Staining for factor VIII (Fig 1, F) confirmed the loss of endothelial cells from the cusp surfaces. The endothelial cells of donor origin were focally present on the cusp surfaces through 10 days after implantation but were rarely seen after 30 days. Reactivity for PCNA was rarely seen after 30 days of implantation (Fig 2, B) and was essentially negative at 20 weeks. The very low reactivity for PCNA in the fibrous sheath indicates that both the endothelial cells and the myofibroblasts (both of host origin) stabilized after a rapid, initial increase in number.

Nick end labeling. The frequency of nick end labeling in endothelial cells and connective tissue cells in unimplanted allografts was extremely low. However, apoptosis, as demonstrated by nick end labeling, was observed in both of these cell types at two days after implantation (Fig 2,C) and reached a peak between 10 and 14 days (Fig 2,D), resulting in nuclear fragmentation and the formation of numerous extracellular and intracellular apoptotic bodies by 30 days of implantation (Fig 2, $E$ and $F$ ). Based on light microscopic morphologic findings, the apoptotic-positive cells were confined to the cuspal fibroblasts and endothelial cells and not inflammatory cells. The apoptotic cells and/or apoptotic bodies were present in all cuspal regions and a selective distribution was not observed. Apoptoticpositive cells were not observed in the fibrous sheath encapsulating the cusp after 20 weeks of implantation. Fibrous sheathing was not present on the cuspal surfaces at the time of the highest incidence of apoptosis but only observed after 20 weeks of implantation, at a time when the cusp was essentially acellular.

Transmission electron microscopic observations. Apoptotic bodies were not observed at 20 weeks. Changes of apoptosis were most clearly demonstrated by means of the nick end labeling techniques and confocal microscopy (Fig 2, $C$ and $F$ ) and were also recognized in hematoxylin and eosin-stained sections (Fig $1, C)$ and by transmission electron microscopy. Transmission electron microscopy was useful in evaluating the occurrence of pyknosis (Fig 3,A) and apoptotic bodies (Fig 3,B) and the changes in the crimping of the valvular collagen (Fig 3, $C$ and $D$ ).

\section{Discussion}

In the present study, the histopathologic and histochemical changes observed after implantation of ovine 


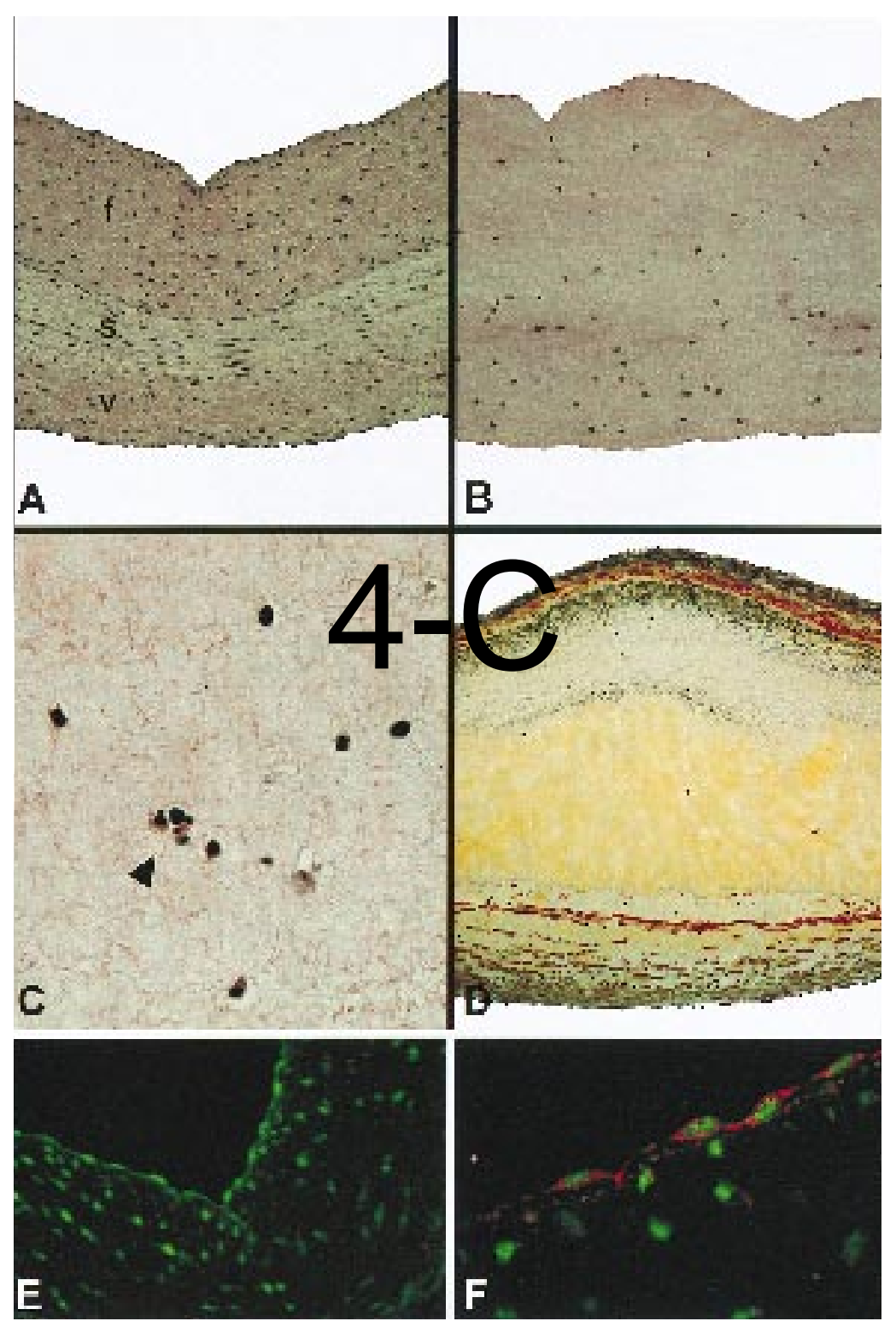

Fig 1. A, Characteristic histologic appearance of a native aortic valve. Three distinct regions are present: the ventricularis $(v)$, the spongiosa $(s)$, and the fibrosa $(f)$. (Hematoxylin and eosin stain; original magnification, $\times 100$.) B, Histologic section of a cryopreserved aortic allograft valve depicts the loss of the trilaminar structure of the cusp after 30 days of implantation. Loss of endothelial cells and a marked reduction in cusp cellularity are apparent. (Hematoxylin and eosin stain; original magnification, $\times 100$.) $\mathbf{C}$, Cryopreserved allograft valve 30 days after implantation. Light micrograph shows pyknotic nuclei and apoptotic bodies in cells having increased cytoplasmic eosinophilia (arrowhead). (Hematoxylin and eosin stain; original magnification, $\times 900$.) D, Light micrograph of a fresh allograft valve implanted for 20 weeks demonstrates a marked loss of cusp cellularity. The cusp is completely encased by a thick fibrous sheath. (Movat pentachrome stain: elastic fibers, black; cellular components, red; proteoglycans, blue; collagen, yellow; mixture of proteoglycans and collagen, blue-green. Original magnification, $\times 100$.) E, Native aortic valve. Confocal image shows PCNA-positive nuclei (green fluorescence) in myofibroblasts and endothelial cells. (Original magnification, $\times 400$.) F, Native aortic valve. High magnification confocal image depicts factor VIII-positive endothelial cells (red cytoplasmic fluorescence) lining the surface of the fibrosa. Note the PCNA-positive nuclei (green fluorescence). (Original magnification, $\times 1000$.) 


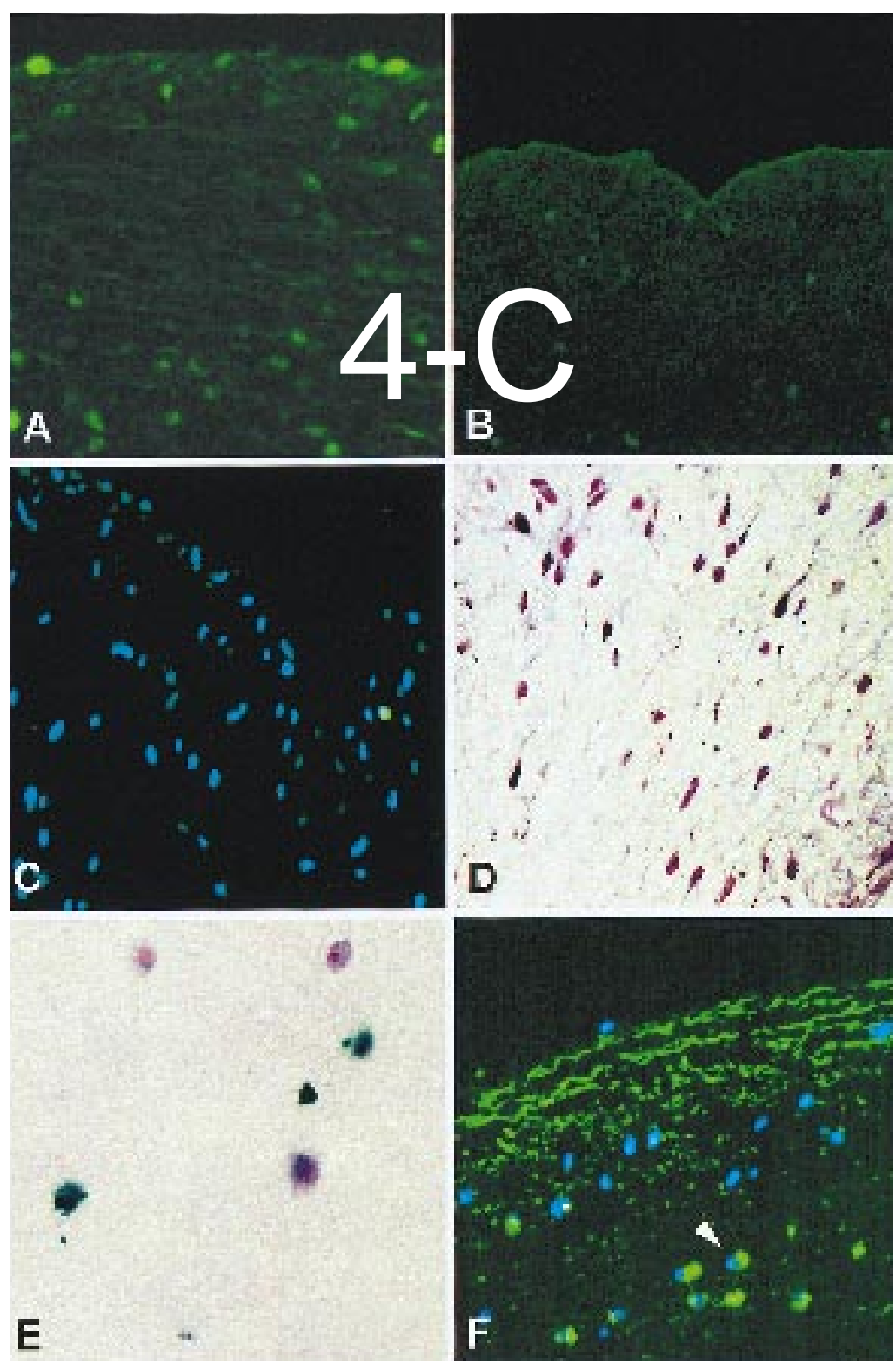

Fig 2. A, Cryopreserved allograft valve after 2 days of implantation. Confocal image demonstrates a marked reduction in the number of PCNA-positive nuclei (green fluorescence) in the spongiosa and ventricularis. (Original magnification, $\times 1000$.) B, Cryopreserved allograft valve implanted for 30 days. Confocal image demonstrates the absence of PCNA-positive nuclei (green fluorescence) and endothelial cells lining the surface of the fibrosa. Note the low level of autofluorescence in the extracellular matrix of the cusp. Compare with Fig 1, $E$ and $F$. (Original magnification, $\times 400$.) C, Cryopreserved allograft valve 2 days after implantation. Confocal image shows an apoptotic nucleus (nick end labeling; green fluorescence). Cusp cellularity within the fibrosa is normal, and nonapoptotic nuclei are demonstrated by staining with DAPI (blue fluorescence). (Original magnification, $\times 400$.) D, Fresh allograft valve 14 days after implantation. Nick end labeling demonstrates apoptotic nuclei (black; peroxidase-labeling) in the spongiosa. Nonapoptotic nuclei have been counterstained with hematoxylin stain. (Original magnification, $\times 630$.) E, Cryopreserved allograft valve 30 days after implantation. High magnification view of apoptotic nuclei and apoptotic bodies stained black by the peroxidase method for nick end labeling. (Original magnification, $\times 1000$.) F, Cryopreserved allograft valve implanted for 30 days. Apoptotic, pyknotic nuclei (nick end labeling; green fluorescence) and intracellular apoptotic bodies (arrowhead) are present in the ventricularis. Cusp cellularity is decreased, as demonstrated by nuclear counterstaining with DAPI (blue fluorescence). Elastic fibers in the ventricularis show moderate yellow autofluorescence. (Original magnification, $\times 400$.) 


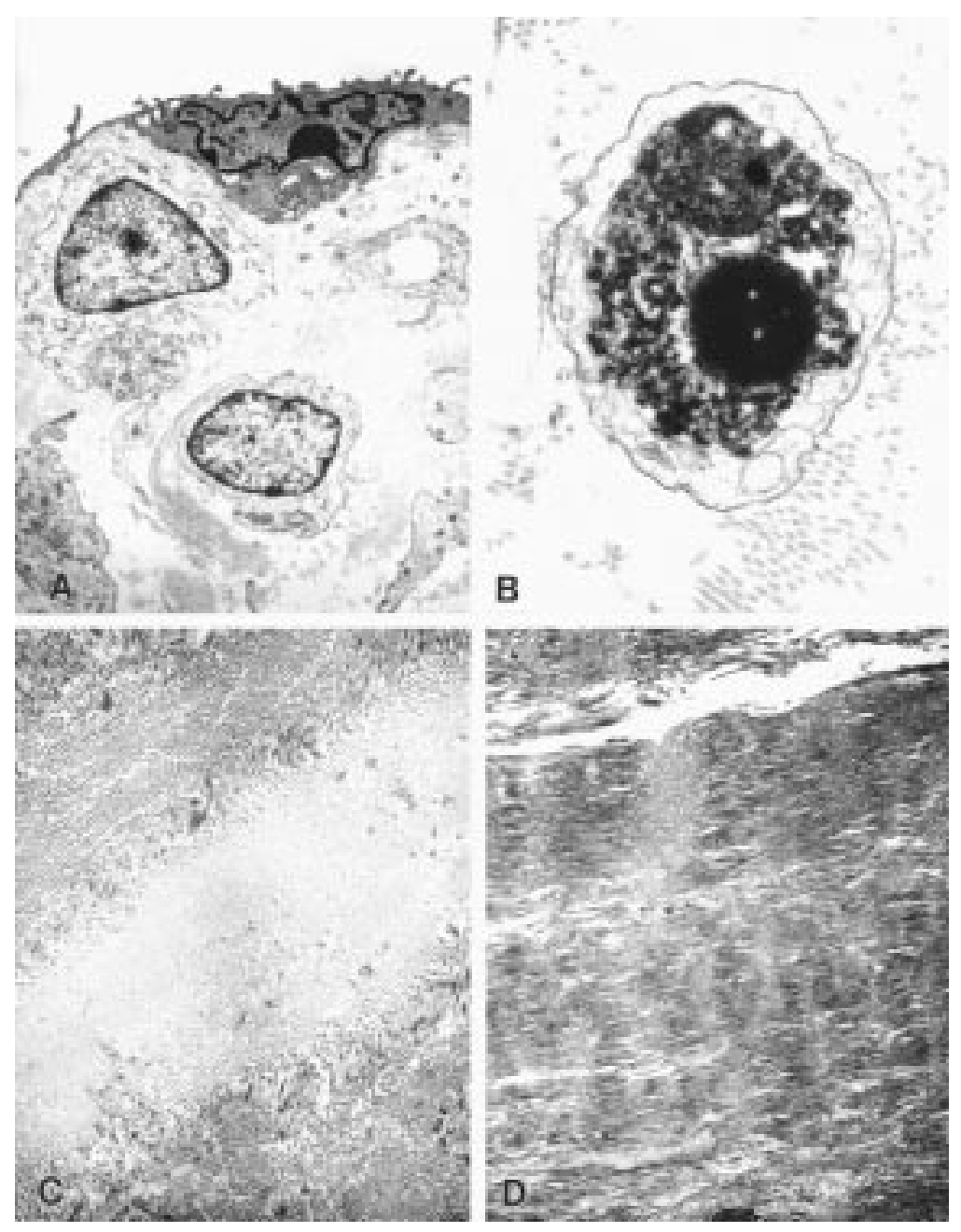

Fig 3. A, Cryopreserved allograft valve implanted for 30 days. Ultrastructural appearance of pyknotic endothelial cell lining the fibrosa. Note marked condensation of the nuclear chromatin and contraction of the cytoplasm. Compare with the normal chromatin of adjacent fibroblasts. (Uranyl acetate/lead citrate stain; original magnification, $\times 4800$.) B, Cryopreserved allograft valve implanted for 30 days. Transmission electron micrograph of a macrophage contains a phagocytosed apoptotic body composed of fragmented nuclear chromatin. (Uranyl acetate/lead citrate stain; original magnification, $\times 10,000$.) Transmission electron micrographs depict changes in the crimping of collagen in the cusps of (C) cryopreserved allograft valves after 30 days of implantation and (D) fresh allograft valves after 20 weeks of implantation. Collagen crimp is preserved at 30 days, although prominent regions of collagen straightening are noted at 20 weeks. (Uranyl acetate/lead citrate stain; original magnification, $[C] \times 3500$ and $[D] \times 2900$.)

aortic allograft valves were similar to those reported in human allograft valves that were used as replacement heart valves or for cardiac reconstruction. ${ }^{2}$ The following findings indicated that apoptosis occurs in the endothelial cells and connective tissue cells of implanted allograft heart valves: (1) nuclear condensation, pyknosis, and fragmentation; (2) formation of intraand extracellular apoptotic bodies, identified by their typical ultrastructural morphologic features and their histochemical reactivity; (3) nick end labeling; and (4) the absence of a significant inflammatory response. ${ }^{6}$ These changes were much more obvious in the connective tissue cells than in the endothelial cells, because many of the latter cells were becoming detached from the cusp surfaces. These findings suggest that apoptosis contributes to the observed loss of cellularity in explanted aortic allograft valves.

Apoptosis (programmed cell death) is a form of cell 
death that plays an important role not only in the normal growth and remodeling of organs but also in normal cell renewal and in a wide variety of pathological conditions. ${ }^{6,9,10}$ The process of apoptosis initially involves the activation of endonucleases that cleave DNA into fragments of specific sizes, known as oligonucleosomes. ${ }^{6}$ These DNA fragments can be detected by the nick end labeling techniques used in the present study. Apoptosis can be promoted or inhibited by a variety of modulating factors, some of which are specific for individual cell types. ${ }^{6,9,10} \mathrm{We}$ are not aware of previous studies of the occurrence of apoptosis in cardiac valvular endothelial cells or connective tissue cells. Nevertheless, it is well established that apoptosis does occur in both of these types of cells in other locations. ${ }^{6}$ In apoptosis, the initial changes of nuclear and cytoplasmic condensation are followed by the fragmentation of nuclei and the formation of apoptotic bodies containing remnants of nuclear material. Thus apoptosis differs from cell necrosis, in which the cell death is associated with cytoplasmic swelling, karyolysis, marked inflammatory reaction, and fibrosis. In contrast, the remnants of apoptotic cells are phagocytosed by adjacent parenchymal cells or by macrophages, leaving no inflammatory reaction, cellular residue, or fibrous scarring. ${ }^{6}$ At least in embryonic and neonatal tissues, this process can be completed within 2 to 3 days. ${ }^{6,9}$

Although the time course of the apoptosis occurring in individual endothelial cells and connective tissue cells was not determined in the present study, we first observed evidence of apoptosis (nuclear condensation and nick end labeling) within 2 days of implantation. It peaked at 10 to 14 days and resulted in a marked loss of cellularity, which was complete by 20 weeks. Therefore it would appear that the apoptosis in allograft valves proceeds at an unusually slow rate (as shown by the maximal occurrence of apoptotic bodies at 30 days). The reason for the slow time course of this apoptosis is not clear; however, the connective tissue cells present in the cusp are very few in number, are widely separated from each other, and have a very limited phagocytic capacity. These characteristics suggest that the removal of apoptotic cells may be very slow in valvular tissues.

Of special interest in the context of these observations are the recently reported comparisons of the histopathologic findings in explanted human cryopreserved allograft valves and in the aortic valves of orthotopically transplanted hearts. ${ }^{2}$ The explanted aortic allograft valves showed the usual changes of nuclear pyknosis and loss of cellularity; however, the valves of transplanted hearts retained their normal morphologic features, even in the presence of fatal allograft rejection. These results can be interpreted as suggesting that apoptosis develops in allograft heart valves, but not in the valves of the orthotopically transplanted hearts. It is possible that immunologic phenomena related to rejection play a role in the occurrence of apoptosis in allograft valves and that this apoptosis may be prevented by the immunosuppressive treatment administered to patients undergoing heart transplantation. Apoptosis of cardiac myocytes has been implicated in the rejection of transplanted hearts, ${ }^{11}$ but no data are available concerning the occurrence of this alteration in the valves of such hearts. Thus detailed studies are needed to clarify the possible role of immunologic injury in triggering apoptosis in allograft valves.

In considering various other causes of apoptosis in allograft valves, the period of hypoxia related to the procurement, disinfection, and cryopreservation of the aortic allograft valves is an important factor to be evaluated. ${ }^{4,5}$ Such a period of hypoxia does not occur during the procurement of heart allografts.

Apoptosis can be triggered and modulated in the heart by a variety of causes, including hypoxia and ischemia plus reperfusion. ${ }^{12}$ Reactive oxygen species, dimethyl sulfoxide, calcium ionophores, calcium calmodulin, and the expression of Fas antigen have been suggested as factors triggering the apoptosis of cardiac myocytes. ${ }^{12}$ Allograft heart valves are exposed to both hypoxia (during harvesting, processing, and storage) and reperfusion-reoxygenation (at the time of implantation and thereafter). However, valvular connective tissue cells, and endothelial cells appear to be much less sensitive than cardiac myocytes to hypoxia. ${ }^{12}$ An initial decrease in cusp cellularity can be attributed to direct and irreversible hypoxic injury and subsequent cell death; however, the cusp cells that have survived the initial hypoxic insult and subsequent tissue processing remain ultrastructurally intact. ${ }^{4}$ Nevertheless, it is possible that subtle hypoxic injury predisposes to the development of apoptosis when the valves are implanted and "reperfused" with oxygenated blood. The possibility that dimethyl sulfoxide promotes apoptosis in cryopreserved valves must be given careful consideration. This agent can either promote $^{13-21}$ or decrease ${ }^{22-24}$ apoptosis, depending on its concentration and on the type of cells to which it is applied. One study ${ }^{13}$ has suggested that concentrations of dimethyl sulfoxide in excess of $2 \%$ definitely increase the frequency of apoptosis. These data have been obtained on noncardiac tissues, and for this reason it is not known how they apply specifically to allograft 
valves. The findings reported in our study suggest that dimethyl sulfoxide and subsequent cryopreservation might not be responsible for initiating apoptosis, because similar findings were observed in both the fresh and the cryopreserved allograft valves. The initiation of apoptosis during allograft harvesting, disinfection, and cryopreservation is suspected, because both fresh and cryopreserved allografts are essentially acellular after 20 weeks of implantation in our animal model and in human allografts. ${ }^{2}$ It remains to be determined whether or not the mechanisms responsible for inducing apoptosis differ in fresh and cryopreserved allograft valves.

We have not tested, in an isolated and controlled fashion, the multiplicity of factors that could be responsible for our observation of apoptosis occurring in both fresh and cropreserved allograft valves. However, our observation does indicate that a continuum of apoptotic changes occurs after implantation in the allograft cuspal cell population. Additional studies addressing the contribution of mechanisms other than apoptosis, such as immune-mediated mechanisms of cell death and ischemic injury, are needed to definitively identify the pathologic mechanism responsible for the loss of allograft cuspal cellularity.

In conclusion, the demonstration of apoptosis-mediated cell death, as presented in this study, suggests that multiple factors associated with the harvesting, processing, and implantation of both fresh and cryopreserved allograft valves may, in fact, contribute to the initiation of apoptosis and the demise of cuspal connective tissue cells and endothelial cells. Systematic examination of the possible contributions of factors that promote or inhibit apoptosis is necessary to develop new techniques for the preservation of cellular viability in valvular allografts and other tissue implants.

We thank Ms Carolyn Jane Bell, National Heart, Lung and Blood Institute, National Institutes of Health, Bethesda, Md, for her editorial assistance with this article and Life Net (Virginia Beach, Va) for the ovine cryopreserved aortic valve allografts.

\section{REFERENCES}

1. O'Brien MF, McGiffin DC, Stafford EG, Gardner MA, Pohlner PF, McLachlan GJ, et al. Allograft aortic valve replacement: longterm comparative clinical analysis of the viable cryopreserved and antibiotic $4^{\circ} \mathrm{C}$ stored valves. J Card Surg 1991;6:534-43.

2. Mitchell RN, Jonas RA, Schoen FJ. Pathology of explanted cryopreserved allograft heart valves: comparison with aortic valves from orthotopic heart transplants. J Thorac Cardiovasc Surg 1998;115:118-27.

3. Hilbert SL, Luna RE, Zhang J, Yining W, Hopkins RA, Yu ZX, et al. Allograft heart valves: assessment of cell viability by confocal microscopy. Circulation 1997;96(suppl):I508.

4. Crescenzo DG, Hilbert SL, Barrick MK, Corcoran PC, St Louis JD, Meissier RHJ Jr, et al. Donor heart valves: electron microscopic and morphometric assessment of cellular injury induced by warm ischemia. J Thorac Cardiovasc Surg 1992; 103:253-8.

5. Domkowski PW, Messier RH Jr, Crescenzo DG, Aly HS, AbdElfattah, Hilbert SL, et al. Preimplantation alteration of adenine nucleotides in cryopreserved heart valves. Ann Thorac Surg 1993;55:413-9.

6. Cummings MC, Winterford CM, Walker NI. Apoptosis. Am J Surg Pathol 1997:88-101.

7. Lange PL, Hopkins RA. Allograft valve banking: techniques and technology. In: Hopkins RA, editor. Cardiac reconstructions with allograft heart valves. New York: Springer-Verlag; 1989. p. 3760.

8. Ferrans VJ, Spray TL, Billingham ME, Roberts WC. Structural changes in glutaraldehyde-treated porcine heterografts used as substitute cardiac valves: transmission and scanning electron microscopic observations in 12 patients. Am J Cardiol 1978;41: 1159-84.

9. Fox JC, Patel VV. Apoptosis and the cardiovascular system. ACC Current Journal Review 1998;7:13-5.

10. Takeda K, Yu ZX, Nishikawa T, Tanaka M, Hosoda S, Ferrans $\mathrm{VJ}$, et al. Apoptosis and DNA fragmentation in the bulbus cordis of the developing rat heart. J Mol Cell Cardiol 1996;28: 209-15.

11. Szabolcs MJ, Ravalli S, Minanov O, Sciacca RR, Michler RE, Cannon PJ. Apoptosis and increased expression of inducible nitric oxide synthase in human allograft rejection. Transplantation 1998;27:804-12.

12. Gottlieb RA, Burleson KO, Kloner RA, Babior BM, Engler RL. Reperfusion injury induces apoptosis in rabbit cardiomyocytes. J Clin Invest 1994:94:1621-8.

13. Lin CK, Kalunta CI, Chen FS, Nguyen TT, Kaptein JS, Lad PM. Dimethyl sulfoxide suppresses apoptosis in Burkitt's lymphoma cells. Exp Cell Res 1995;216:403-10.

14. Chatterjee D, Han Z, Mendoza J, Goodglick L, Hendrickson EA, Pantazis $\mathrm{P}$, et al. Monocytic differentiation of HL-60 promyelocytic leukemia cells correlates with the induction of Bcl-XL. Cell Growth Differ 1997;8:1083-9.

15. Czene S, Tiback M, Harms-Ringdahl M. pH-dependent DNA cleavage in permeabilized human fibroblasts. Biochem J 1997; 15;237-41.

16. Yamada T, Kondoh N, Matsumoto M, Yoshida M, Mackawa A, Oikawa T. Overexpression of PU.1 induces growth and differentiation inhibition and apoptotic cell death in murine erythroleukemia cells. Blood 1997;89:1383-93.

17. Trubiani O, Ciancarelli M, Rapino M, Di Primio R. Dimethyl sulfoxide induces programmed cell death and reversible G1 arrest in the cell cycle of human lymphoid pre-T cell line. Immunol Lett 1996;50:51-7.

18. Ginestier-Verne C, Chateau MT, Bureau JP. Implication of tyrosine kinases and protein kinase $\mathrm{C}$ in dimethyl sulfoxide-induced apoptosis. Anal Cell Pathol 1996;11:115-26.

19. Koike M, Ishino K, Kohno Y, Tachikawa T, Kartasova T, Kuroki $\mathrm{T}$, et al. DMSO induces apoptosis in SV40-transformed human keratinocytes, but not in normal keratinocytes. Cancer Lett 1996;108:185-93. 
20. Chateau MT, Ginestier-Verne C, Chiesa J, Caravano R, Bureau JP. Dimethyl sulfoxide-induced apoptosis in human leukemic U937 cells. Anal Cell Pathol 1996;10:75-84.

21. Nishizawa Y, Saeki K, Hirai H, Yazaki Y, Takafu F, Yuo A. Potent inhibition of cell density-dependent apoptosis and enhancement of survival by dimethyl sulfoxide in human myeloblastic HL-60 cells. J Cell Physiol 1998;174:135-43.

22. Watson RW, Redmond HP, Wang JH, Condron C, Bouchier-
Hayes D. Neutrophils undergo apoptosis following ingestion of Escherichia coli. J Immunol 1996;156:3986-92.

23. Bour ES, Ward LK, Cornman GA, Isom HC. Tumor necrosis factor-alpha-induced apoptosis in hepatocytes in long-term culture. Am J Pathol 1996;148:485-95.

24. Powell CB, Herzog TJ, Scott JH, Collins JL. Evidence for a protein synthesis-dependent and -independent TNF alpha cytolytic mechanism. Gynecol Oncol 1995;58:327-35. 